\title{
Application of Maximum Likelihood and Spectral Angle Mapping Classification Techniques to Evaluate Forest Fire Severity from UAV Multi-spectral Images in South Korea
}

\author{
Heesung Woo, ${ }_{1}^{1}$ Mauricio Acuna, ${ }^{2}$ Buddhika Madurapperuma, ${ }^{3}$ \\ Geonhwi Jung, ${ }^{4}$ Choongshik Woo, ${ }^{5}$ and Joowon Park ${ }^{4 *}$ \\ ${ }^{1}$ College of Forest and Environmental Sciences, Kangwon National University, \\ 1 Kangwondaehak-gil, Chuncheon-si, Gangwon-do 24341, Korea \\ ${ }^{2}$ Forest Research Institute, University of the Sunshine Coast, \\ Locked Bag 4, Maroochydore DC, QLD 4558, Australia \\ ${ }^{3}$ Department of Forestry and Wildland Resources, Humboldt State University, \\ 1 Harpst Street, Arcata, CA 95521, USA \\ ${ }^{4}$ School of Forest Science and Landscape Architecture, Kyungpook National University, \\ 80 Daehakro, Bukgu, Daegu 41566, Korea \\ ${ }^{5}$ Forest Disaster Management Division, Forest Conservation Department, National Institute of Forest Science, \\ 57, Hoegi-ro, Dongdaemun-gu, Seoul 02445, Korea
}

(Received March 17, 2021; accepted May 17, 2021; online published May 28, 2021)

Keywords: forest fire, UAV, remote sensing, accuracy assessment, machine learning

High-resolution unmanned aerial vehicle (UAV) multi-spectral sensor images can provide valuable information for mapping forest areas that have recently been burned. In this study, we investigate the use of multi-spectral images captured with a UAV to evaluate burn severity in areas affected by forest fires in Gumi-si, South Korea. Fire classification was performed using two supervised learning algorithms, maximum likelihood (ML) and spectral angle mapper (SAM). Three spectral indices, namely, normalized difference vegetation index (NDVI), RedEdge NDVI (RE-NDVI), and the visible-band difference vegetation index (VDVI), were used to create burn severity thresholds in ML and SAM classifiers. The classification results indicated that ML has higher overall accuracy $(80-89 \%$, Kappa coefficient $=0.8)$ than SAM (44-52\%, Kappa coefficients $\sim 0.27$ ) in identifying fire severity classes. The ML classifier showed higher accuracy for both unburned and crown fire classes, whereas the SAM classifier exhibited moderate accuracy for all classes. Most of the misclassification was identified between the unburned area and the low heat-damaged area. This research revealed that distinguishing between the unburned area and low heat-damaged area is the most challenging task in fire severity classification. Also, further investigation is required to improve the accuracy of fire severity classification from multi-spectral images.

\section{Introduction}

Globally, catastrophic forest fires are on the rise and have become an important issue in many countries. For example, Australia recorded historical severe uncontrolled fires from June 2019 to

*Corresponding author: e-mail: jwnpark@gmail.com https://doi.org/10.18494/SAM.2021.3365 
March 2020. The fires burned an estimated 18.6 million hectares and destroyed over 56,900 buildings and houses. ${ }^{(1)}$ Wildfires in the western United States have greatly increased in number and size over the past three decades due to warmer weather, high wind speeds, fuel accumulation, and lightning. ${ }^{(2,3)}$ In South Korea, from 2004 to 2018, there were 6,588 forest fires with a total burned area estimated at around 11,065 ha and an economic loss estimated at 252 million USD. ${ }^{(4)}$ Most forest fires have human causes, including smoking, recreation, and illegal burning in suburban regions in South Korea. Additionally, fanned by strong winds, fires spread to the mountains in the eastern coastal area of South Korea. ${ }^{(5)}$

The frequency, size, and severity of wildfires have increased over the past few decades as a consequence of climate change and human activities, ${ }^{(6)}$ with approximately one billion animals and birds killed and some endangered species exposed to the risk of extinction in New South Wales, Australia. ${ }^{(1)}$ Forest fires can have other indirect consequences, including landslides and soil erosion. For instance, it has been confirmed that the water infiltration capacity of soil declines after a forest fire, ${ }^{(7-9)}$ which results in increased runoff and surface erosion. ${ }^{(7,10-13)}$ To reduce these consequences of forest fires, it is necessary that strategic plans are developed to investigate burned areas and the severity of damage so that efficient recovery plans can be implemented in damaged and burned areas. Additionally, precise estimates of fire damage levels also provide valuable information for efficient restoration planning after a fire. ${ }^{(14,15)}$ Furthermore, foresters have developed algorithms to estimate the mean return time, and precise burn severity maps are useful for predicting the recovery time and planning reforestation to facilitate best forest management practices.

In general, integrated field surveys and satellite imagery analysis are the preferred methods to analyze forest fire severity in large areas of burned forest. ${ }^{(16,17)}$ However, several factors limit the use of field and satellite imagery methods, such as time consumption, labor cost, the cost of high-resolution images, and the low quality of contaminated images due to meteorological factors such as clouds and rain. To overcome these issues, unmanned aerial vehicles (UAVs) equipped with high-resolution sensors have been proposed as an alternative to satellite images for different applications in the forestry sector, including fire severity assessment. ${ }^{(4,18,19)}$

Previous forest fire severity research has been performed using satellite or airborne multispectral imagery. Most of this research investigated burn severity by comparing pre- and postforest-fire spectral indices, such as the normalized difference vegetation index (NDVI) and the normalized burn ratio (NBR). ${ }^{(20-25)}$ Additionally, most of the fire severity studies combined NBR and the burned area index (BAI) since shortwave infrared bands have the potential to detect forest fire damage. ${ }^{(26-28)}$ According to Keeley, fire severity is defined as the impact of a fire on ecosystems, such as tree mortality or loss of diversity. ${ }^{(29)}$ Rozario et al. developed a method of site-specific burn severity modeling using remote sensing techniques to develop severity patterns on vegetation and soil in a fire-prone region of Palo Verde National Park in Guanacaste, Costa Rica. ${ }^{(30)}$ They examined physical terrain features, soil cover, and scorched vegetation characteristics to develop a fire risk model and quantify probably burned areas. ${ }^{(30)}$ In forestry, fire severity is generally evaluated on the basis of the degree of tree mortality, canopy loss, or bole and crown scorch. ${ }^{(29)}$ In the United States, the Forest Service (USFS) has categorized fire severity into five classes (extreme, high, moderate, low, and unburned) on the basis of a 
composite burn index. ${ }^{(31-33)}$ These studies also revealed the current limitations in identifying or classifying fire severity using low-resolution satellite imagery data. ${ }^{(4)}$

In this context, we investigate the opportunities for using multi-spectral UAV images to assess fire severity. The spectral angle mapper (SAM) and maximum likelihood (ML) classification techniques are used to assess fire severity, and the analysis includes an accuracy comparison between the two methods. The paper also highlights which methods and aspects are worth investigating to improve the application of multi-spectral images for fire severity assessment. It is anticipated that the insights obtained from the approaches presented in this paper will contribute to increased understanding of the technical aspects and potential benefits of UAV sensor technology for fire severity assessment.

\section{Materials and Methods}

\subsection{Study sites}

The study was conducted on April 1-5, 2019, within the perimeter of a large wildfire that occurred in Gumi-si, located in Goa-eup in South Korea on March 28, 2019, which caused a total estimated fire-damaged area of 176.6 ha. The climate of Gumi-si is dry and windy during winter and spring, and Korean red pine (Pinus densiflora) and Japanese larch (Larix kaempferi) are the predominant species in this region. The satellite image in Fig. 1 shows the total fire-damaged area one day after the forest fire occurred. This image was captured by the Sentinel-2A imaging satellite, which is operated by the European Space Agency (ESA). The sensor can capture images with a spatial resolution of $10 \mathrm{~m}$ and 13 bands (coastal aerosol, blue, green, red, vegetation RedEdge, near-infrared, short-wave infrared, etc.). The study area in which images were collected with the UAV (190.4 ha) is marked in red in Fig. 1.

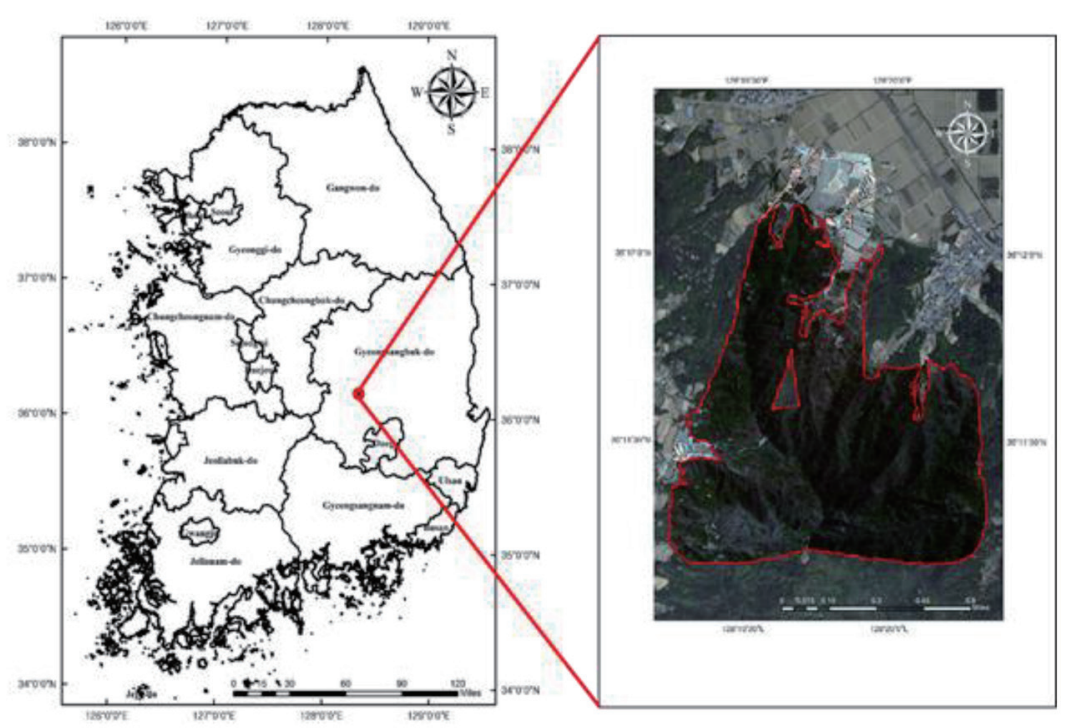

Fig. 1. (Color online) Study area in which satellite images were collected after forest fire (Gumi-si, Goa-eup, South Korea) and satellite image. 


\subsection{Data collection}

\subsubsection{UAV machine specifications and imaging system description}

A NIFoS-2 UAV equipped with a RedEdge camera (Micasense, Seattle, WA, USA) was used to acquire the multi-spectral images. The images were acquired on May 11, 2019, more than one month after the forest fire. The acquired images consisted of 225 scenes with $70 \%$ overlap and $70 \%$ sidelap. The RedEdge camera can collect images in five bands (blue, green, red, RedEdge, and near-infrared), which are considered appropriate for vegetation detection. The spatial resolution was set to $30 \mathrm{~cm}$ with a flying height of over $500 \mathrm{~m}$ above sea level. The images were then preprocessed and converted into a mosaicked reflectance image using Pix4D software (Pix4 S.A., Prilly, Switzerland). Figures 2(a) and 2(b) present the RedEdge multi-spectral UAV images of the burned areas in Gumi-si collected on May 11, 2019. The images were generated with a pseudo-infrared composite using the NIR band (RGB = bands 5, 3, 2). The UAV was a hexacopter, equipped with six rotor arms, which provide a stable flight and more lifting power. UAV specifications and dimensions are presented in Fig. 3(a). The maximum flight time, speed, and altitude were limited to $30 \mathrm{mins}, 15 \mathrm{~m} / \mathrm{s}$, and $1000 \mathrm{~m}$, respectively.

\subsubsection{Definition of fire severity}

Fire severity was determined by adopting the Korean composite burn index (KCBI) and the field survey results. According to the KCBI, fire severity is categorized into five levels: unburned, low, moderate, high, and extreme. There is a limitation in applying the KCBI for fire severity assessment due to an ambiguous definition between the moderate- and low-severity classes. ${ }^{(4)}$ To avoid this problem, only four fire severity classes were used in this study (unburned, low heat-damaged, extreme heat-damaged, and crown fire), to reflect the significant characteristics of the damage degree. These four fire severity classes are defined as follows:

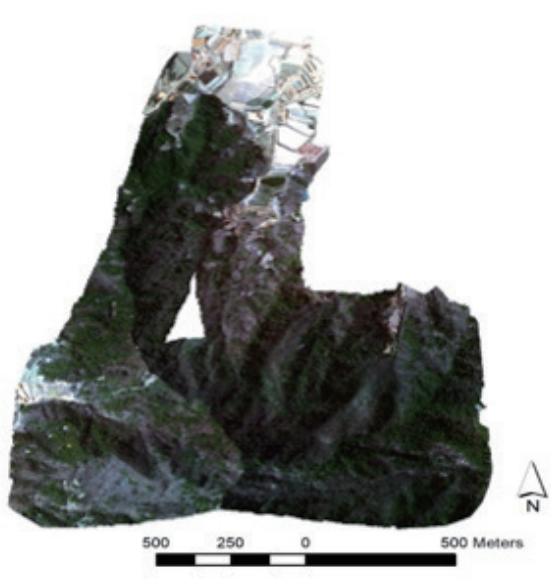

(a)

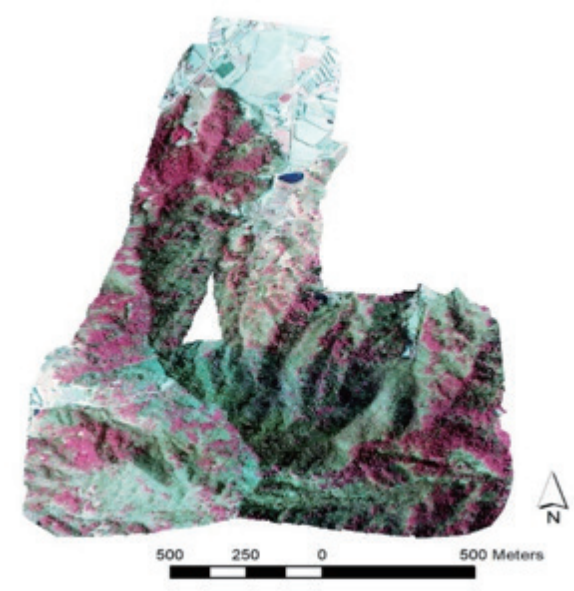

(b)

Fig. 2. (Color online) (a) Natural color composite: $\mathrm{RGB}=$ bands 3, 2, 1 and (b) pseudo-infrared composite: RGB = bands 5, 3, 2 of RedEdge multispectral images of the burned areas in Gumi-si. 


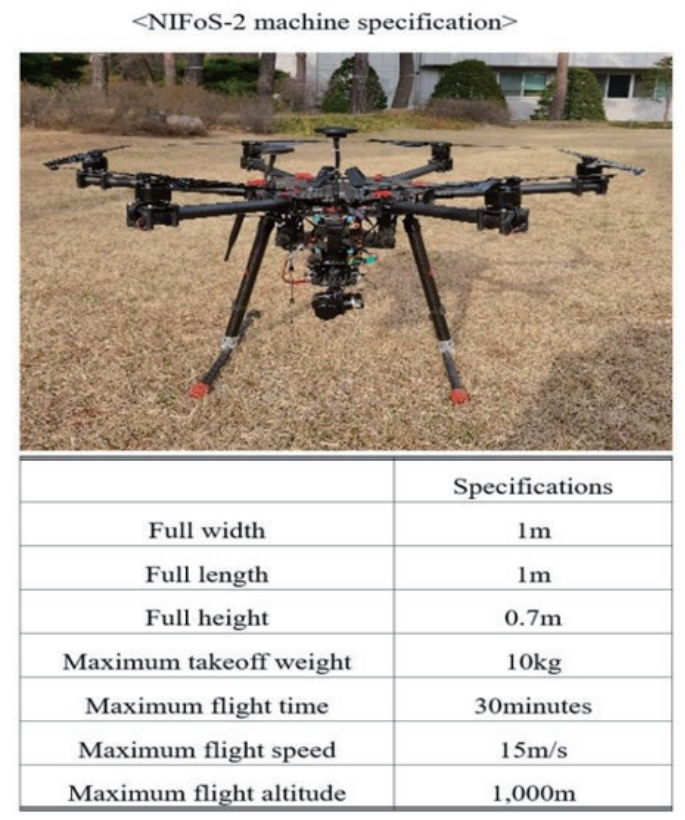

(a)

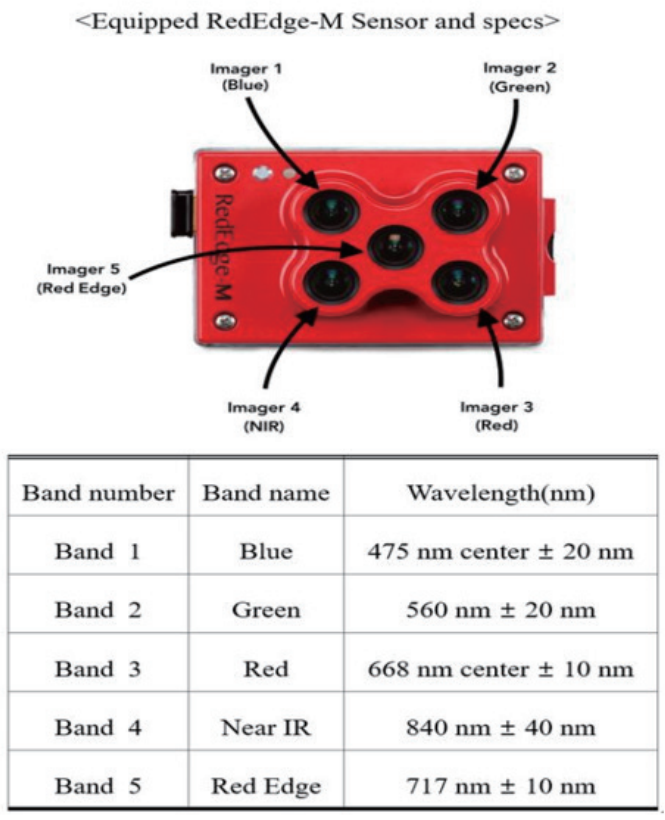

(b)

Fig. 3. (Color online) Specifications of (a) NIFoS-2 and (b) RedEdge-M multi-spectral sensors.

- Unburned: no presence of damaged areas or evidence of forest fire

- Low heat-damaged: the presence of ash and soot on the ground surface

- Extreme heat-damaged: the presence of fallen yellow leaves due to heat damage

- Crown fire: evidence of crown fire (no leaves and trunks covered by soot)

\subsubsection{Field survey}

Ground control points (GCPs) were collected during the field survey to represent different fire severity locations. The GCPs of the above four different burn severity classes were targeted to classify the fire severity. The location of sampling sites was determined using a random sampling method. To develop training data for classification and validate the fire severity results, ten locations in each fire severity class (determined by random sampling) were visited, and their geographic coordinates recorded. The borderline between the burned and unburned areas was delineated on the basis of the images captured during the field survey (Fig. 4(a)).

\subsection{Spectral analysis}

The overall schematic approach to analyze forest fire severity using UAV multi-spectral images is presented in Fig. 5. Mosaicked reference images captured by the UAV were merged and overlapped using Pix4D software. Integrated images were processed with atmospheric correction using ENVI ${ }^{\circledR} 5.3$ and ArcGIS $^{\odot}$ 10.8.1 software. To investigate the spectral characteristics of each fire severity class, the mean and standard deviation of the NDVI, 


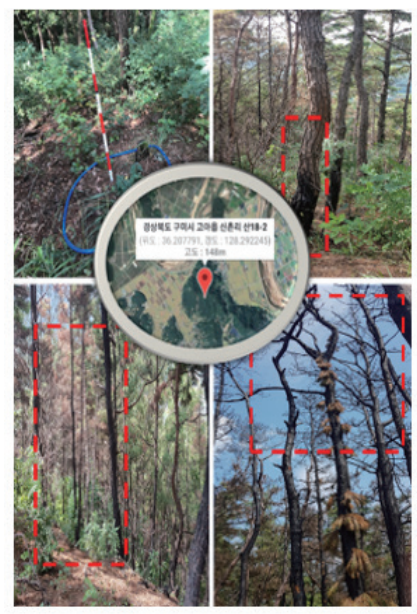

(a)

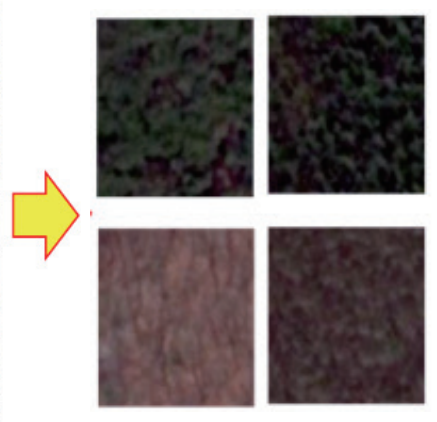

(b)

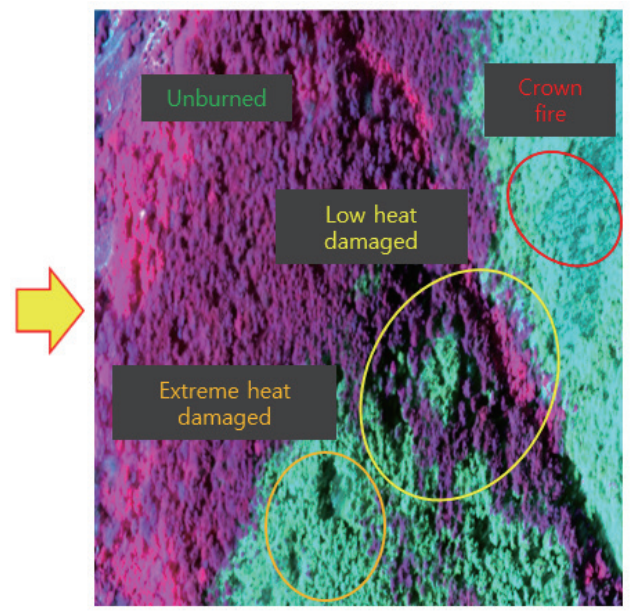

(c)

Fig. 4. (Color online) Development process of the training data: (a) Collection of geocoordinate data from locations with different levels of fire severity (unburned, low heat-damaged, extreme heat-damaged, and crown fire), (b) fire severity library developed from UAV and field survey geocoordinate data, and (c) reference map generated from the developed library and UAV images.

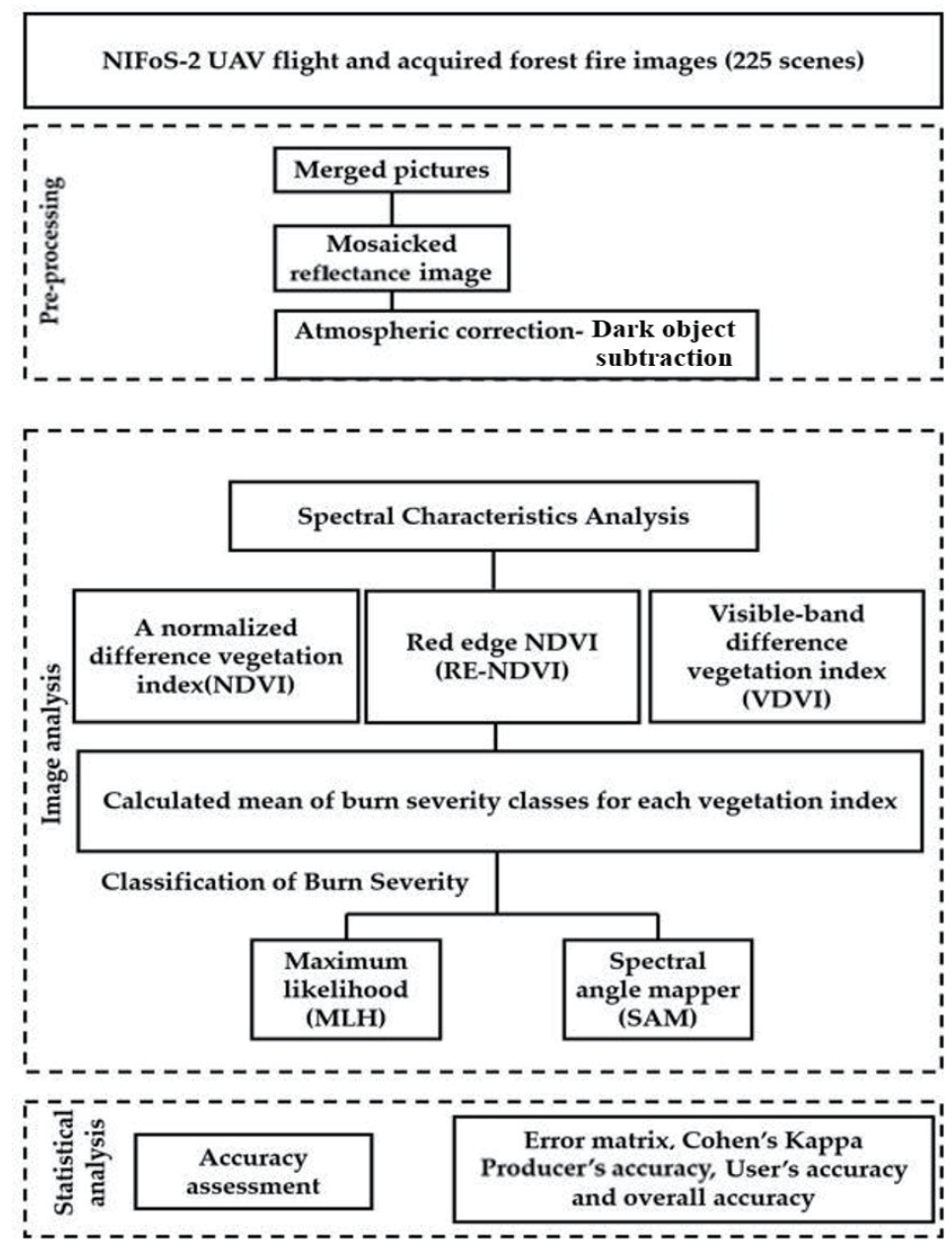

Fig. 5. Overall flowchart of forest fire severity analysis. 
RedEdge (RE) NDVI, and visible-band difference vegetation index (VDVI) were calculated using the multi-spectral UAV imagery. The vegetation indices are defined as

$$
\begin{gathered}
N D V I=\frac{\rho N I R-\rho \operatorname{Re} d}{\rho N I R+\rho \operatorname{Re} d}, \\
R E-N D V I=\frac{\rho N I R-\rho \operatorname{Red} \text { edge }}{\rho N I R+\rho \operatorname{Red} \text { edge }}, \\
V D V I=\frac{2 \times \rho \text { Green }-\rho \text { Red }-\rho \text { Blue }}{2 \times \rho \text { Green }+\rho \text { Red }+\rho \text { Blue }},
\end{gathered}
$$

where $\rho$ is the mean reflectance of each band.

A composite image was created using each spectral band and stacked UAV imagery (for example, the NDVI mean band and UAV image consist of six bands of a composite image). Next, the composite image was used to classify burn severity with the training data using the ML and SAM classification techniques. Finally, an accuracy assessment was conducted using statistical analysis, which included the error matrix, Cohen's Kappa, and overall accuracy. A detailed description of the methodologies is provided in the following sections.

\subsubsection{Reflectance value selection}

Image reflectance spectra were used to assess the quality of training data (i.e., digitized and GCPs) for fire severity classes while applying the ML and SAM algorithms. Reflectance values were sourced from the ground truth data collected during the field survey. Four reflectance values were identified from the study area corresponding to the four fire severity classes. The spectral signatures of the burn severity classes are presented in Fig. 6. The reflectance pattern

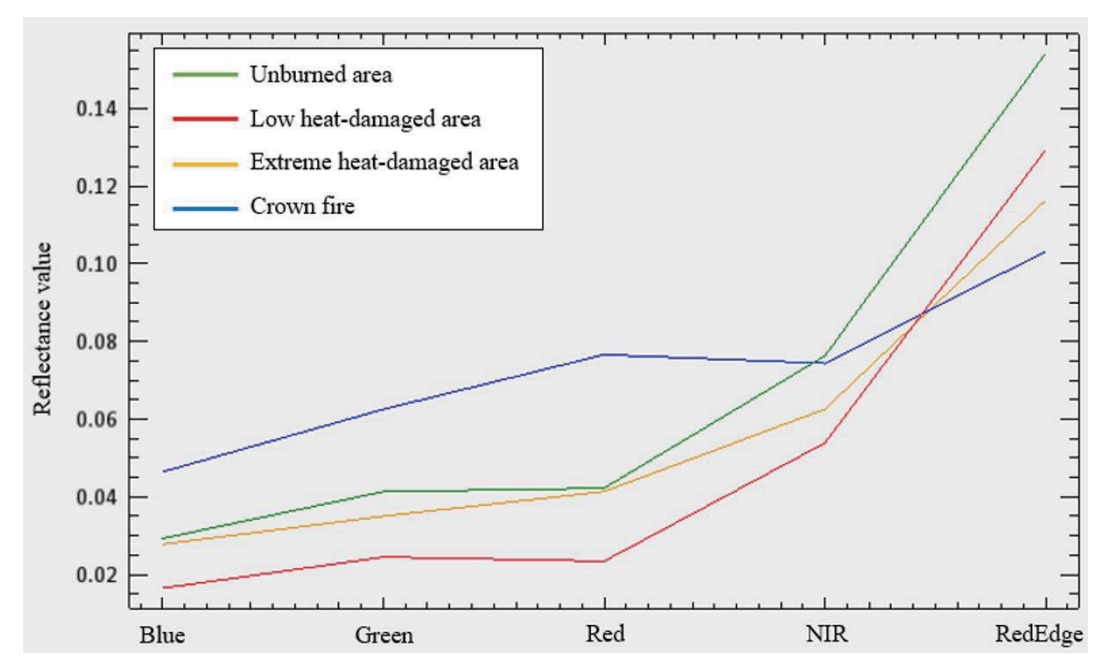

Fig. 6. (Color online) Spectral reflectance value selection for pixel-based classification. 
shows that crown fire had the highest reflectance in the blue, green, and red bands, while unburned areas had the highest reflectance value in the NIR and RedEdge bands. Additionally, compared with the low heat-damaged areas, the extreme heat-damaged areas had higher reflectance values except in the RedEdge band.

\subsubsection{Training and testing classifiers from UAV image samples}

Some samples from the set of collected UAV images were used to train and test the classifiers. To embrace all the reflectance values, sampling was conducted in such a way that enough pixels were included from all the defined fire severity classes (unburned area, low heat-damaged area, extreme heat-damaged area, and crown fire). Twenty-five plots were selected from each fire severity class from the field survey data and the visual classification at the study locations in Gumi-si. Each plot was $3 \times 3$ pixels in size. Table 1 presents the mean and standard deviation of the fire severity for three spectral indices, where mean values were estimated from training samples. NDVI shows more distinct values among the burn severity classes than RE NDVI and VDVI. Therefore, NDVI is useful in classifying burn severity since the index can easily define thresholds among classes.

\subsection{Classification of burn severity}

\subsubsection{Maximum likelihood algorithm}

The ML algorithm allocates a pixel to the class that has the highest probability under the assumption that the reflectance values of each class have a normal (Gaussian) distribution in the band. ${ }^{(4)}$ The probability for the pixel is analyzed by the multivariate normal density function from the mean, variance, and covariance of training samples. ${ }^{(34)}$ The equation used for ML classification is

$$
\mathrm{P}\left(X \mid \omega_{i}\right)=\frac{1}{\frac{n}{(2 \pi)^{2}\left|V_{i}\right|^{\frac{1}{2}}}} \exp \left[-\frac{1}{2}\left(X-M_{i}\right)^{T} V_{i}^{-1}\left(X-M_{i}\right)\right]
$$

where $n$ is the number of multi-spectral bands, $X$ is the unknown measurement vector, $V_{i}$ is the covariance matrix of each training class, and $M_{i}$ is the mean vector of each training class.

Table 1

Mean of fire severity for NDVI, RE NDVI, and VDVI vegetation indices.

\begin{tabular}{lcccc}
\hline Index & Crown fire & Extreme heat-damaged & Low heat-damaged & Equation \\
\hline NDVI & $0.238 \pm 0.011$ & $0.486 \pm 0.024$ & $0.753 \pm 0.011$ & $0.666 \pm 0.015$ \\
RE NDVI & $0.206 \pm 0.010$ & $0.330 \pm 0.019$ & $0.392 \pm 0.022$ & $0.373 \pm 0.019$ \\
VDVI & $0.004 \pm 0.009$ & $0.009 \pm 0.016$ & $0.203 \pm 0.040$ & $0.153 \pm 0.016$ \\
\hline
\end{tabular}




\subsubsection{Spectral angle mapper}

Fire severity was assessed from multi-spectral images collected in areas of Gumi-si damaged by fire. These areas were identified using a target detection analysis through spectral reflectance values. The spectral reflectance was derived from the UAV multi-spectral images, and each fire severity class was identified on the basis of the reflectance value and wavelength of the images (Fig. 6). In the SAM approach, the similarity values of the spectral angle between the reference spectrum and the image spectrum of each pixel were calculated. The SAM algorithm can be presented as a mathematical formula representing a pure impulse function between the image pixel and the reference reflectance spectrum as follows: ${ }^{(35)}$

$$
\alpha=\cos ^{-1} \frac{\sum X Y}{\sqrt{\sum(X)^{2}(Y)^{2}}},
$$

where $\alpha$ is the angle between the reference and captured image spectra, $X$ is the UAV image spectrum, and $Y$ is the reference image spectrum.

\subsection{Accuracy assessment}

Fire severity accuracy was evaluated using an error matrix method that provided accuracy parameters including confusion matrices, user and producer accuracies, Kappa coefficient values, and overall accuracies for the target areas. ${ }^{(30)}$ The total number of cells in each burn severity class was set out in a square array of rows and columns. The rows in the matrix represent the reference data (NDVI classified map), while the columns represent the allocated (mapped) classes. The maps of two classified vegetation indices (i.e., NDVI and RE NDVI) were aggregated using the Combine function in the Spatial Analyst extension of ArcMap 10.8.1. The attribute table of the resulting calculation was exported as a. $\mathrm{dbf}$ file. ${ }^{(36)}$ Then the. $\mathrm{dbf}$ file was imported in Microsoft Excel, the confusion matrix was generated using the Pivot Table, and the Kappa coefficient value was obtained as follows:

$$
\hat{K}=\frac{N \sum_{i=1}^{k} x_{i i}-\sum_{i=1}^{k}\left(x_{i+} \times x_{+i}\right)}{N^{2}-\sum_{i=1}^{k}\left(x_{i+} \times x_{+i}\right)},
$$

where $K$-hat is the coefficient of agreement, $N$ is the total number of sites in the matrix, $k$ is the number of rows in the matrix, $x_{i i}$ is the number in row $i$ and column $i, x_{+i}$ is the total for row $i$, and $x_{i+}$ is the total for column $i$.

Usually, the accuracy is assessed by using an error matrix. In our study, the error matrix was developed by selecting a sample of pixels from polygons in the target images and obtaining the reference classification for each forest fire severity location, where the classified forest severity was defined as the best available assessment of the ground condition. ${ }^{(37)}$ We assumed the pixel as the assessment unit, and the developed matrix provided the classification accuracy. Also, the 
Kappa coefficient value was used to evaluate the viability of the classification compared with a random classification, subject to the observed marginal in the true classes.

\section{Results}

\subsection{Identified fire severity in Gumi-si}

Fire severity maps were generated using the two classification methods with three vegetation index thresholding methods. Figures 7 and 8 present the classification results of ML and SAM using NDVI, RE NDVI, and VDVI, respectively. ML shows good classification results for overall classes; the estimated overall accuracies of the ML and SAM methods were $80-89 \%$ (Kappa coefficient $=0.8$ ) and $44-52 \%$ (Kappa coefficient $\sim 0.27$ ), respectively. The accuracy results of the ML classification method are presented in Tables 2 and 3. Regarding the ML

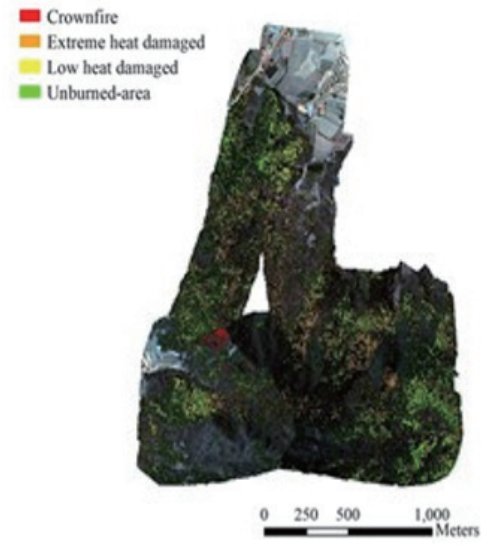

(a)

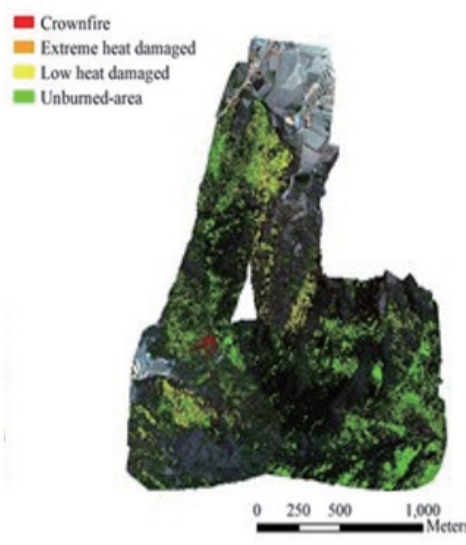

(b)

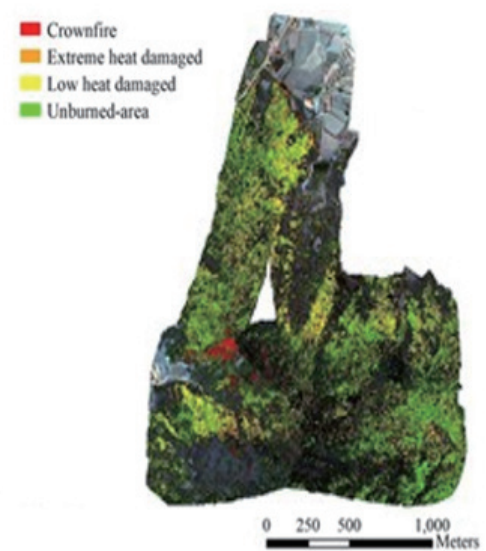

(c)

Fig. 7. (Color online) Identified fire severity using ML method in Gumi-si: (a) NDVI, (b) RE NDVI, and (c) VDVI.

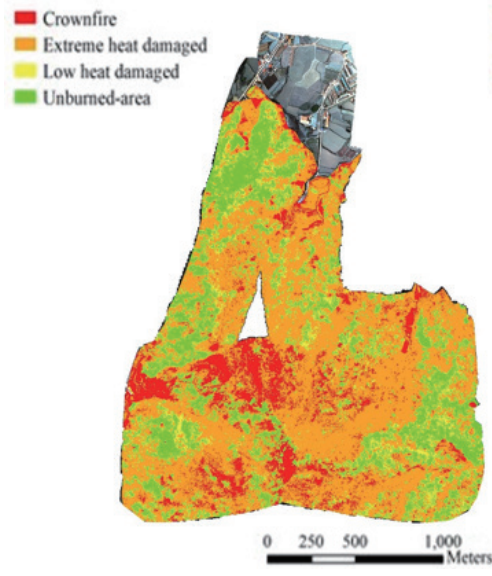

(a)

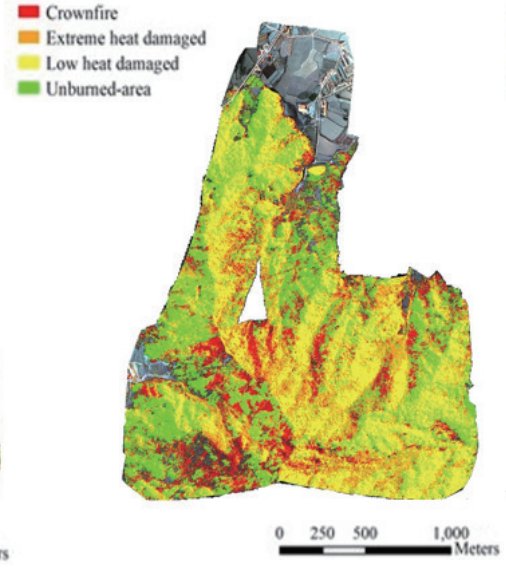

(b)

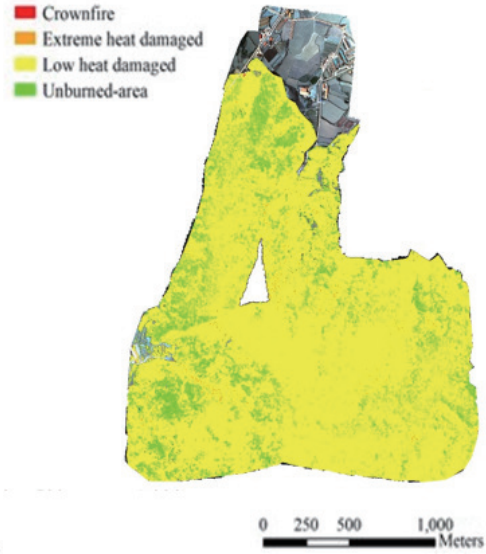

(c)

Fig. 8. (Color online) Identified fire severity using SAM method in Gumi-si: (a) NDVI, (b) RE NDVI, and (c) VDVI. 
Table 2

Confusion matrix of NDVI (Reference) and RE NDVI for classification accuracy assessment for ML (\%) in Gumisi.

\begin{tabular}{lcccccc}
\hline $\begin{array}{l}\text { Reference } \\
\text { Classifications }\end{array}$ & Unburned & $\begin{array}{c}\text { Low heat- } \\
\text { damaged }\end{array}$ & $\begin{array}{c}\text { Extreme heat- } \\
\text { damaged }\end{array}$ & Crown fire & $\begin{array}{c}\text { Producer } \\
\text { accuracy }\end{array}$ & $\begin{array}{c}\text { User } \\
\text { accuracy }\end{array}$ \\
\hline Unburned & 90.31 & 3.81 & 0.41 & 0.04 & 90.31 & 98.41 \\
Low heat-damaged & 0.33 & 84.17 & 1.25 & 0 & 84.17 & 98.66 \\
Extreme heat-damaged & 9.36 & 12.02 & 98.33 & 0.46 & 98.33 & 35.39 \\
Crown fire & 0.00 & 0 & 0 & 99.50 & 99.5 & 99.95 \\
Total & 100.00 & 100.00 & 100.00 & 100.00 & - & - \\
\hline
\end{tabular}

Overall accuracy $=89.42 \%$, Kappa coefficient $=0.80$

Table 3

Confusion matrix of NDVI (Reference) and VDVI for classification accuracy assessment for ML (\%) in Gumi-si.

\begin{tabular}{lcccccc}
\hline $\begin{array}{l}\text { Reference } \\
\text { Classifications }\end{array}$ & Unburned & $\begin{array}{c}\text { Low heat- } \\
\text { damaged }\end{array}$ & $\begin{array}{c}\text { Extreme heat- } \\
\text { damaged }\end{array}$ & Crown fire & $\begin{array}{c}\text { Producer } \\
\text { accuracy }\end{array}$ & $\begin{array}{c}\text { User } \\
\text { accuracy }\end{array}$ \\
\hline Unburned & 92.46 & 3.37 & 0.12 & 0.94 & 92.46 & 98.13 \\
Low heat-damaged & 0.32 & 67.74 & 0.47 & 0.53 & 67.74 & 98.46 \\
Extreme heat-damaged & 7.14 & 28.89 & 99.41 & 15.17 & 98.41 & 62.10 \\
Crown fire & 0.08 & 0 & 0 & 83.36 & 83.36 & 98.19 \\
Total & 100.00 & 100.00 & 100.00 & 100.00 & - & - \\
\hline
\end{tabular}

Overall accuracy $=87.16 \%$, Kappa coefficient $=0.80$

classification, the unburned and crown fire classes showed the highest accuracy $(>80 \%)$ for both user and producer. Compared with the ML classification, the SAM classification resulted in lower overall accuracy (Tables 4 and 5), with the unburned and crown fire classes having the highest accuracy (Table 5).

Most of the misclassification occurred between the extreme heat-damaged area and the low heat-damaged area in both the ML and SAM methods. These results revealed that the classification and allocation of pixels to extreme heat-damaged and low heat-damaged areas are the most challenging tasks in fire severity assessment. The results also indicated that the use of multi-spectral imaging data is limited to discriminating between unburned and low heatdamaged areas since the crown fire and extreme heat-damaged areas have very similar reflectance patterns and values based on multi-spectral images. To improve the accuracy of the classification method in the low heat-damaged area, it is necessary to factor in external elements such as under-canopy inventory and crown density, which can provide additional information to recognize the differences between unburned and low heat-damaged areas accurately.

Regarding the SAM classification, the extreme heat-damaged area showed the highest accuracy level (80.56\%) among the fire severity classes for NDVI and RE NDVI, whereas for NDVI and VDVI, the highest accuracy $(100 \%)$ was estimated for both the extreme heat-damaged and crown fire classes (Table 5). However, most of the misclassification occurred for the low heat-damaged and crown fire classes when using NDVI and RE NDVI (Table 4). These results revealed that the classification and allocation of pixels to low heat-damaged and crown fire areas are the most challenging tasks when using NDVI and RE NDVI in fire severity assessment. NDVI and RE NDVI thresholding showed high accuracy for the extreme heat-damaged and 
Table 4

Confusion matrix of NDVI (Reference) and RE NDVI for classification accuracy assessment for SAM (\%) in Gumisi.

\begin{tabular}{lcccccc}
\hline $\begin{array}{l}\text { Reference } \\
\text { Classifications }\end{array}$ & Unburned & $\begin{array}{c}\text { Low heat- } \\
\text { damaged }\end{array}$ & $\begin{array}{c}\text { Extreme heat- } \\
\text { damaged }\end{array}$ & Crown fire & $\begin{array}{c}\text { Producer } \\
\text { accuracy }\end{array}$ & $\begin{array}{c}\text { User } \\
\text { accuracy }\end{array}$ \\
\hline Unburned & 47.24 & 18.23 & 0.88 & 0 & 47.24 & 70.22 \\
Low heat-damaged & 8.25 & 22.48 & 3.59 & 0 & 22.48 & 68.84 \\
Extreme heat-damaged & 44.38 & 55.57 & 80.56 & 70.96 & 80.55 & 29.50 \\
Crown fire & 0.13 & 3.71 & 14.97 & 29.04 & 29.04 & 48.89 \\
Total & 100.00 & 100.00 & 100.00 & 100.00 & - & - \\
\hline
\end{tabular}

Overall accuracy $=43.78 \%$, Kappa coefficient $=0.26$

Table 5

Confusion matrix of NDVI (Reference) and VDVI for classification accuracy assessment for SAM (\%) in Gumi-si.

\begin{tabular}{lcccccc}
\hline $\begin{array}{l}\text { Reference } \\
\text { Classifications }\end{array}$ & Unburned & $\begin{array}{c}\text { Low heat- } \\
\text { damaged }\end{array}$ & $\begin{array}{c}\text { Extreme heat- } \\
\text { damaged }\end{array}$ & Crown fire & $\begin{array}{c}\text { Producer } \\
\text { accuracy }\end{array}$ & $\begin{array}{c}\text { User } \\
\text { accuracy }\end{array}$ \\
\hline Unburned & 81.57 & 21.33 & 0 & 0 & 81.57 & 74.10 \\
Low heat-damaged & 13.59 & 24.89 & 0 & 0 & 24.89 & 66.27 \\
Extreme heat-damaged & 4.85 & 53.77 & 100 & 0 & 100 & 0.02 \\
Crown fire & 0.08 & 0 & 0 & 100 & 100 & 100 \\
Total & 100.00 & 100.00 & 100.00 & 100.00 & - & -
\end{tabular}

Overall accuracy $=52.24 \%$, Kappa coefficient $=0.27$

crown fire classes in the ML method (Table 2), while NDVI and VDVI thresholding showed high accuracy for these fire severity classes in the SAM method (Table 4). The misclassification of fire severity was due to the use of a pattern of spectral reflectance rather than an absolute value of reflectance for each fire severity class in the SAM method. ${ }^{(4)}$ NDVI and RE NDVI showed the lowest overall accuracy among the classification accuracy assessments in SAM (Table 4). This was caused by confusion between low heat-damaged and crown fire areas resulting from the similar NDVI values for areas with fire damage or a discolored crown. Also, the similar reflectance values and patterns of unburned and low heat-damaged areas were caused by misclassification, which increased the amount of misclassification (Table 4).

\section{Discussion}

We investigated forest fire severity using ML and SAM techniques to evaluate classification accuracy using UAV multi-spectral images taken in South Korea. The result indicated that the ML method presented the highest fire severity accuracy level $(>80 \%)$ for both users and producers. Even though SAM showed low overall accuracy, predictions in the unburned and crown fire classes showed that its classification accuracy is acceptable.

The misclassification between unburned and low heat-damaged areas and between extreme heat-damaged and crown fire areas indicated that several sets of training data are required to increase the overall accuracy of fire severity classification in the ML method. However, in the case of SAM, the accuracy was more affected by the spectral patterns of fire severity classes than by the quantity of training sample data. 
According to Shin et al., ${ }^{(4)}$ the NDVI thresholding method showed superior performance to ML and SAM in forest fire detection and classification. Moreover, as previously reported, we also revealed that NDVI and RE NDVI have moderate accuracy with the ML and SAM methods. Therefore, the combination of NDVI, RE NDVI, and VDVI is expected to estimate forest fire damage with a higher accuracy level in a limited time. To achieve this, further studies including more survey and training data are required to generalize the threshold for application in forest fire severity classification.

UAVs are more cost-effective than satellite or airborne imaging in generating high-resolution multi-spectral images. The application of UAVs will enhance forest fire restoration plans by providing cost-effective and high-quality data. Additionally, the high-resolution images collected with UAVs will provide high-quality training data, increasing the accuracy of classification results.

High-quality training data will enhance the use of machine learning or deep learning algorithms for the detection of damaged areas of forest and for post-fire monitoring research to a national or state level. The Korean government is planning to launch a new earth observation satellite mission in 2023 involving the CAS500 satellite (CAS: compact advanced satellite), which will focus on forested and agricultural areas. In preparation for the use of CAS500 in forestry and agriculture, further research must be conducted on the use of high-resolution multispectral images in both sectors.

\section{Conclusions}

We investigated the use of multi-spectral UAV images to assess forest fire severity. Two supervised learning techniques, the SAM and ML methods, were used for this purpose. The results indicated that ML has high accuracy for fire severity classification while SAM has moderate overall accuracy. In the Gumi-si region, ML was more effective than SAM in identifying the crown fire and extreme heat-damaged areas.

Regarding the ML method, the highest accuracy was obtained for the crown fire class. Despite these promising results, there were some issues in establishing the classification limit between some areas (e.g., the unburned area and the low heat-damaged area) in both the SAM and ML methods. Thus, further research is required to improve the accuracy of fire severity classification from multi-spectral images. It is also necessary to factor in other elements such as under-canopy inventory and crown density, which can provide additional information for the accurate classification of damaged areas (e.g., unburned and low heat-damaged areas).

\section{Acknowledgments}

This research was supported by the Korea Forest Service (Korea Forestry Promotion Institute) [2019149B10-2123-0301 and 2019151A00-2123-0301] and National Institute of Forest Science [FE0500-2018-05]. 


\section{References}

1 More Than One Billion Animals Killed in Australian Bushfires: https://www.sydney.edu.au/news-opinion/ news/2020/01/08/australian-bushfires-more-than-one-billion-animals-impacted.html (accessed August 2020).

2 T. Schoennagel, J. K. Balch, H. Brenkert-Smith, P. E. Dennison, B. J. Harvey, A. Krawchuk, N. Mietkiewicz, P. Morgan, M. A. Moritz, R. Rasker, M. G. Turner, and C. Whitlock: PNAS 114 (2017) 4582. https://doi. org/10.1073/pnas.1617464114

3 J. E. Keeley and A.D. Syphard: Fire Ecol. 15 (2019) 24. https://doi.org/10.1186/s42408-019-0041-0

4 J. I. Shin, W. W. Seo, T. Kim, and J. Park: Forests 10 (2019) 1025. https://doi.org/10.3390/f10111025

5 J. W. Kim and C. Jung: J. Asia-Pac. Entomol. 11 (2018) 77. https://doi.org/10.1016/j.aspen.2008.05.003

6 K. T. Weber and R. Yadav: Remote Sens. 12 (2020) 2959. https://doi.org/10.3390/rs12182959

7 P. Marxer, M. Conedera, and D. Schaub: Proc. 14th Conf. Fire and Forest Meteorology (III International Conference on Forest Fire Research, Coimbra, 1998) 1317-1331. https:/www.dora.lib4ri.ch/wsl/islandora/ object/wsl:17823

8 L. F. DeBano: Water Repellent Soils: a State-of-the-art (Pacific Southwest Forest and Range Experiment Station, Calilfornia, 1981) 1st ed., Chap. 1.

9 A. Cerdà: Hydrol. Processes 12 (1998) 1031. https://doi.org/10.1002/(SICI)1099-1085(19980330)12:4<661::AIDHYP607>3.0.CO;2-7

10 S. Maria and J. L. Rubio: Selection of Papers from Int. Conf. Soil Erosion and Degradation as a Consequence of Forest Fires (Geoforma Ediciones, Logroño, 1994) 15-27.

11 G. Giovannini, R. Vallejo, S. Lucchesi, S. Bautista, S. Ciompi, and J. Llovet: For. Ecol. Manage. 147 (2001) 15. https://doi.org/10.1016/S0378-1127(00)00437-0

12 B. Soto, R. Basanta, E. Benito, R. Perez, and F. Diaz-Fierros: Soil Erosion as a Consequence of Forest Fires, Eds. S. Maria and J. L. Rubio (Geoforma Ediciones, Logroño, 1994) pp. 91-98.

13 A. Cerdà: Zeitschrift für Geomorphologie 42 (1998) 373. https://doi.org/10.1127/zfg/42/1998/373

14 U. Alganci, E. Sertel, and C. Ormeci: Proc. 30th European Association of Remote Sensing Laboratories Symp. - Remote Sensing for Science, Education, and Natural and Cultural Heritage (EARSel, 2010) 423.

15 D. P. Roy, Y. Jin, P. E. Lewis, and C. O. Justice: Remote Sens. Environ. 97 (2005) 137. https://doi.org/10.1016/j. rse.2005.04.007

16 R. KumarJaiswal, S. Mukherjee, K. D. Raju, and R. Saxena: Int. J. Appl. Earth Obs. Geoinf. 4 (2002) 1. https:// doi.org/10.1016/S0303-2434(02)00006-5

17 J. Loschiavo, B. Cirulis, Y. Zuo, B. A. Hradsky, and J. D. Stefano: Int. J. Wildland Fire 26 (2017) 491. https:// doi.org/10.1071/WF16167

18 A. Matese, P. Toscano, S. F. Di Gennaro, L. Genesio, F. P. Vaccari, J. Primicerio, C. Belli, A. Zaldei, R. Bianconi, and B. Gioli: Remote Sens. 7 (2015) 2971. https://doi.org/10.3390/rs70302971

19 E. R. Hunt, W. D. Hively, S. J. Fujikawa, D. S. Linden, C. S. T. Daughtry, and G. W. McCarty: Remote Sens. 2 (2010) 290. https://doi.org/10.3390/rs2010290

20 M. J. L. García and V. Caselles: Geocarto Int. 6 (1991) 31. https://doi.org/10.1080/10106049109354290

21 P. M. Barbosa, D. Stroppiana, J. Grégoire, and J. M. C. Pereira: Global Biogeochem. Cycles 13 (1999) 933. https://doi.org/10.1029/1999GB900042

22 C. J. Chafer, M. Noonan, and E. Macnaught: Int. J. Wildland Fire 13 (2004) 227. https://doi.org/10.1071/ WF03041

23 J. Epting, D. Verbyla, and B. Sorbel: Remote Sens. Environ. 96 (2005) 328. https://doi.org/10.1016/j. rse.2005.03.002

24 B. M. Collins, M. Kelly, J. W. van Wagtendonk, and S. L. Stephens: Landscape Ecol. 22 (2007) 545. https://doi. org/10.1007/s10980-006-9047-5

25 B. N. Tran, M. A. Tanase, L. T. Bennett, and C. Aponte: Remote Sens. 10 (2018) 1680. https://doi.org/10.3390/ $\underline{\text { rs10111680 }}$

26 E. Chuvieco, M. P. Martín, and A. Palacios: Int. J. Remote Sens. 23 (2002) 5103. https://doi. org $/ 10.1080 / 01431160210153129$

27 C. Amos, G. P. Petropoulos, and K. P. Ferentinos: Int. J. Remote Sens. 40 (2019) 905. https://doi.org/10.1080/01 431161.2018.1519284

28 F. Filipponi: Proc. 2nd Int. Electronic Conf. Remote Sensing 2 (2018) 364-370. https://doi.org/10.3390/ecrs-205177

29 J. E. Keeley: Fire in Encyclopedia of Ecology, S. E. Jørgensen and B. D. Fath, Eds. (Elsevier, Amsterdam, 2008) pp. 1557-1564.

30 P. F. Rozario, B. D. Madurapperuma, and Y. Wang: Remote Sens. 10 (2018) 4127. https://doi.org/10.3390/ rs10091427 
31 F. C. Rossi, A. Fritz, and G. Becker: Sustainability 10 (2018) 2227. https://doi.org/10.3390/su10072227

32 R. H. Fraser, J. V. Sluijs, and R. J. Hall: Remote Sens. 9 (2017) 279. https://doi.org/10.3390/rs9030279

33 P. McKenna, P. D. Erskine, A. M. Lechner, and S. P.hinn: Int. J. Remote Sens. 38 (2017) 4244. https://doi.org/1 $0.1080 / 01431161.2017 .1317942$

34 P. H. Swain, and S. M. Davis: IEEE Trans. Pattern Anal. Mach. Intell. 3 (1981) 713. https://doi.org/10.1109/ TPAMI.1981.4767177

35 R. H. Yuhas, A. F. H. Goetz, and J. W. Boardman: Proc. Summaries 3rd Annu. JPL Airborne Geosci. Workshop 1 (1992) 147.

36 P. G. Oduor, L. Kotchman, A. Nakamura, S. Jenkins, and G. Ale: For. Policy Econ. 20 (2012) 36. https://doi. org/10.1016/j.forpol.2012.02.005

37 P. L. Zimmerman, I. W. Housman, C. H. Perry, R. A. Chastain, J. B. Webb, and M. V. Finco: Remote Sens. Environ. 128 (2013) 176. https://doi.org/10.1016/j.rse.2012.09.017

\section{About the Authors}

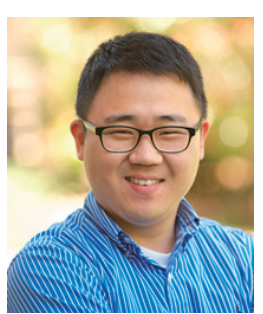

Heesung Woo received his B.S. degree from Kangwon National University, South Korea, in 2011 and his first and second M.S. degrees from Kangwon National University, South Korea, in 2013 and Humboldt State University, CA, USA, in 2015, respectively. He received his Ph.D. degree from the University of Tasmania, Australia, in 2020. From 2019 to 2020, he was a research professor at Kyungpook National University, South Korea. Since 2021, he has been a research professor at Kangwon National University. His research interests are in precision forestry, value chain optimization, and data analysis in forest management. (whs1608@gmail.com)

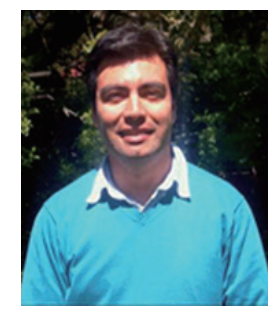

Mauricio Acuna received his B.S. degree from University Austral of Chile in 1997, his M.S. degree from University of Chile in 2004, and his Ph.D. degree from Oregon State University, USA, in 2006. From 2006 to 2012, he was a research fellow at the University of Tasmania, Australia, and since 2012, he has been a senior research fellow and senior lecturer at the University of the Sunshine Coast, Australia. His research interests include timber and wood supply chain optimization, forest planning optimization, forest and fire management optimization, sensor technology, artificial intelligence and computer vision, and forest operations. (macuna@usc.edu.au)

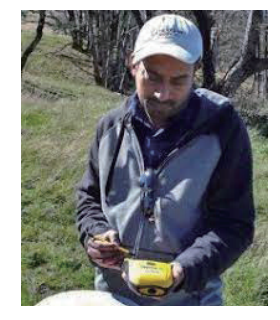

Buddhika Madurapperuma received his B.S. degree from the University of Kelaniya, Sri Lanka, in 2000, his M.S. degree from the University of Peradeniya, Sri Lanka, in 2005, and his Ph.D. degree from North Dakota State University, USA, in 2013. From 2013 to 2014, he was a postdoctoral researcher at Purdue University, USA. Since 2015, he has been a lecturer at Humboldt State University. His research interests are in forest ecology, GIS, and remote sensing. (bdm280@humboldt.edu) 


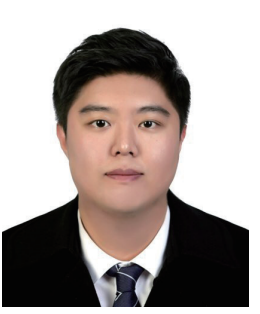

Geonhwi Jung received his B.S. and M.S. degrees from Kyungpook National University, South Korea, in 2017 and 2020, respectively. Since 2020, he has been working on his doctorate. His research interests are in RS/GIS, forest measurement, and forest fires. (alzaki3050@knu.ac.kr)

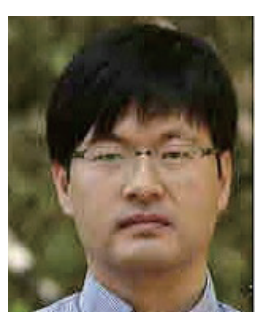

Choongshik Woo received his B.S. degree from Konkuk University, South Korea, in 2004 and his M.S. and Ph.D. degrees from Inha University, South Korea, in 2006 and 2011, respectively. He is currently a senior researcher at the National Institute of Forest Science (NIFoS). His research interests are in remote sensing and forest fires. (woocs@korea.kr)

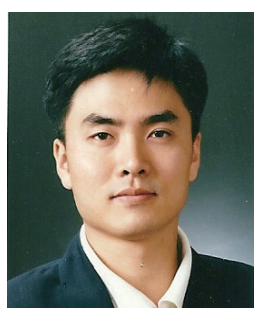

Joowon Park received his B.S. and M.S. degrees from Seoul National University, South Korea, in 1995 and 2000, respectively, and his Ph.D. degree from the University of Washington, WA, USA, in 2011. Since 2012, he has been a professor at Kyungpook National University. His research interests are in RS/GIS, forest management, forest inventory, and international forestry. (jwnpark@gmail.com) 